\title{
DISORDERS OF THE ELECTRICAL CONDUCTION SYSTEM OF THE HEART - A SIGNIFICANT PROBLEM IN AVIATION MEDICINE
}

\author{
Michał A. KUREK, Ewelina ZAWADZKA-BARTCZAK, Katarzyna BARWIŃSKA, Daria \\ OWSIAK \\ Department of Internal Disease, Military Institute of Aviation Medicine, Warsaw, Poland
}

Source of support: Own sources

Author's address: M. Kurek, Department of Internal Disease, Military Institute of Aviation Medicine, Krasińskiego 54/56 Street, 01-755 Warsaw, Poland, e-mail: mkurek@wiml.waw.pl

Abstract: Disorders of the electrical conduction system of the heart are a relatively common electrocardiographic abnormality found during aviation medical examinations and one of the reasons for the loss of pilot licenses/licenses to fly. At the same time, the type of arrhythmia and/or cardiac conduction disorders alone usually does not provide a sufficient basis for the performance/continuation of certain professional duties. This paper discusses the pathogenesis of disorders of the electrical conduction system of the heart, types of arrhythmias, their classification, therapeutic and aviation medical certification procedure in some of them, and the possible prognosis in potentially harmless arrhythmias and/or conduction disorders registered in standard ECG, which require more detailed diagnostics in the flying staff population. It may turn out that they constitute certain restrictions or even contraindications to flying

Keywords: supraventricular arrhythmias, ventricular arrhythmias, atrioventricular blocks, intraventricular blocks, flying staff 


\section{INTRODUCTION}

Cardiovascular diseases are the most common cause of loss of flying licenses, out of which rhythm disorders constitute a significant percentage [24].

Disorders of the electrical conduction system of the heart are the most often easily recognizable changes in electrocardiographic recording. They concern electrophysiological phenomena resulting from disturbances in the production or conduction of stimuli in the heart.

Among arrhythmia and cardiac conduction disorders we distinguish sinus rhythm disorders, increased non-sinus stimulation, reentry phenomena, atrioventricular and sinoatrial blocks [7]. Traditionally, the simplest division of this pathology is to distinguish supraventricular and ventricular arrhythmias. Supraventricular arrhythmias (SAs) are: supraventricular extrasystoles, supraventricular tachycardia, atrial flutter and fibrillation. Ventricular arrhythmias (VAs) are divided into single (premature or substitute) and complex (couplets and ventricular tachycardias, ventricular flutter and fibrillation). For clinical purposes, taking into account the quantitative and qualitative aspects, VAs can be systematized according to several types of classifications.

Lowne's classification for quantitative and qualitative evaluation during a 24-hour Holter ECG recording:

1. Level 0 - no ventricular ectopic systoles

2. Level 1 - less than 30 ventricular ectopic systoles per hour

3. Level 2 - more than 30 ventricular ectopic systoles per hour

4. Level 3: 3A - various ventricular systoles $3 B$ - ventricular bigeminy

5. Level 4: 4A - couplets of ventricular systoles $4 \mathrm{~B}$ - salvos ( 3 and more consecutive systoles)

6. Level 5 - early premature ventricular systoles of the R/T type

Bigger's classification [29] additionally takes into account the presence or absence of organic heart disease and the assessment of the risk of sudden cardiac death. Depending on the coexisting factors, the same type of ventricular arrhythmia can be classified as mild, potentially malignant or malignant rhythm disorder (table 1).

Although Bigger's classification of VAs takes into account the coexistence of many factors, it has certain limitations. It does not include genetically conditioned heart diseases, in which there are VAs and a risk of sudden cardiac death in the absence of organic heart disease, such as in ion channelopathies: long QT syndrome, short QT syndrome, Brugada syndrome, catecholaminergic polymorphic ventricular tachycardia.

For certification and prognosis reasons, Breithard's division of ventricular arrhythmias [29] seems interesting, which apart from prognosis also includes the possibility of therapy.

Breithard's division:

1. Ventricular tachycardias in patients without structural heart disease:

- with a curable cause: idiopathic right ventricular outflow tract tachycardia and idiopathic left ventricular tachycardia,

- with an uncurable causee: long QT syndrome, short QT syndrome, catecholaminergic polymorphic ventricular tachycardia Brugada syndrome.

2. Ventricular tachycardia in patients with structural heart disease:

- in ischemic and post-infarction conditions, treatable through revascularization or ablation,

- in non-ischaemic cardiomyopathies (hypertrophic cardiomyopathy, dilated cardiomyopathy, arrhythmogenic right ventricular cardiomyopathy), which cannot be permanently cured.

It should be emphasized that a number of disorders of the electrical conduction system of the heart occur in clinically healthy individuals and are a variant of the norm depending on age. Examples are presented in table 2 [29].

In everyday clinical practice it is also important that arrhythmias may occur asymptomatically or in the form of a number of ailments, from mild

Tab. 1. Bigger's clinical division of arrhythmia.

\begin{tabular}{cccc}
\hline & mild & potentially malignant & malignant \\
\hline arrhythmia & PVC, nsVT & PVC, nsVT & sVT, VF, PVC, nsVT \\
\hline heart disease & absent or minimal & present & present \\
\hline LV dysfunction & absent & various degrees & present \\
\hline SCD risk & minimal & various degrees & present \\
\hline
\end{tabular}

LV - left ventricle, nsVT - non-sustained ventricular tachycardia, PVC - premature ventricular contraction, SCD - sudden cardiac death, sVT - sustained ventricular tachycardia, VF - ventricular fibrillation 
Kurek M. et al. - Disorders of the electrical...

Tab. 2. Disorders of the electrical conduction system of the heart occur in clinically healthy individuals and are a variant of the norm depending on age.

\begin{tabular}{|c|c|c|c|}
\hline $20-30$ years old & $31-40$ years old & $41-60$ years old & $>60$ years old \\
\hline level I A-V block & level I A-V block & level I A-V block & \\
\hline \multicolumn{4}{|c|}{$\begin{array}{l}\text { Wenckebach Phenomenon (most often } \\
\text { during sleep) }\end{array}$} \\
\hline \multirow[t]{2}{*}{$\begin{array}{l}\text { ventricular extrasystoles }<50 / 24 \mathrm{~h} \text {, } \\
\text { various shapes }\end{array}$} & $\begin{array}{l}\text { ventricular extrasystoles }<100 / 24 \mathrm{~h} \text {, } \\
\text { various shapes }\end{array}$ & $\begin{array}{l}\text { ventricular extrasystoles }<100 / 24 \mathrm{~h} \text {, } \\
\text { various shapes }\end{array}$ & \\
\hline & & $\begin{array}{l}\text { supraventricular extrasystoles } \\
<100 / 24 \mathrm{~h}\end{array}$ & $\begin{array}{l}\text { supraventricular extrasystoles } \\
<1000 / 24 \mathrm{~h}\end{array}$ \\
\hline
\end{tabular}

Tab. 3. List of disorders and impairments from the scope of disorders of the electrical conduction system of the heart in the assessment of physical fitness for air and ground flight assistance services and aviation engineering services.

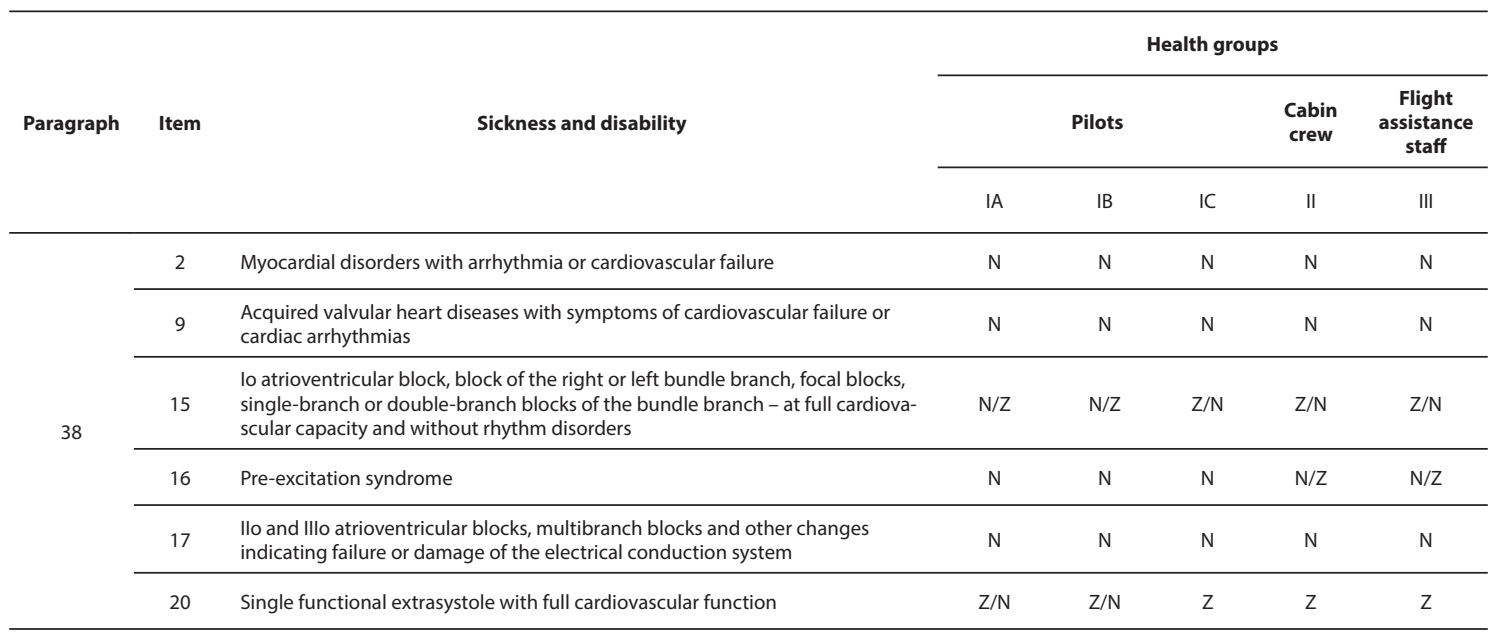

Z - capable; $\mathrm{N}$ - permanently or temporarily uncapable

to severely affecting human functioning. In the case of military flying staff, this is of considerable importance, especially in the case of supersonic aircraft pilots performing tasks in extreme environmental conditions - during accelerations in the $\mathrm{Gz+} /$ - axis (mainly head and legs). Symptoms of arrhythmia depend on the frequency of ventricular rhythm, duration and individual sensitivity of the patient. The most common symptoms include: palpitations, fatigue, dizziness, chest discomfort, dyspnea, weakness or fainting [12].

Conduction disorders can be divided into three main groups: sinus node dysfunction (sinus bradycardia, Wenckebach-type sinoatrial block, Mobitz II-type sinoatrial block, sinus inhibition), atrioventricular blocks (lo block, Wenckebach Phenomenon - Ilo block or Mobitz II - Ilo block, block IIlo) and intraventricular blocks (block of anterior or posterior branch, block of the right or left bundle branch). The accompanying symptoms also depend on many factors, including the age of the patient, the presence of organic heart disease, the degree of physical activity and the type and degree of bradycardia.

Military pilots are a carefully selected group of people with an initial thorough assessment of the cardiovascular system, supplemented by ECG, echocardiography and electrocardiographic exercise tests. They are subject to routine, annual check-ups. Electrocardiographic monitoring of cardiac activity is also carried out during highly specialized examinations performed for the purpose of medical certification and/or in connection with the need to maintain the ability to serve in the air (examination in a low-pressure chamber, training increasing overload tolerance). It should be noted that CAs and/or conduction disorders in pilots, as in the general population, are most often detected accidentally. Such a fact usually results in suspension of the duties performed by the pilot until the etiology of cardiac arrhythmias is clarified, and if they are considered important 
and potentially reversible, also until their remission/cure. The role of the physician and the certifier is essential in this respect in order to ensure that appropriate vigilance is exercised in detecting heart rhythm disorders that may affect flight safety, especially in the case of single-person flights. The relevant provisions governing the matter of ability to perform tasks in the air in the army are included in the regulation of the Minister of National Defense (table 3) [33].

In civil aviation, people with symptomatic sinus node dysfunction, complete atrioventricular block, symptomatic symptomatic QT prolongation and implanted ICD are considered unable to fly [32]. Rhythm and conduction disturbances such as: periodic or permanent sinus dysfunction, atrial fibrillation or flutter, asymptomatic sinus inhibition, left bundle branch block, Mobitz 2-type atrioventricular block, tachycardia with broad or narrow QRS syndromes, pre-excitation syndrome, asymptomatic QT prolongation, suspected Brugada syndrome, additional cardiological evaluation is required for licensing.

\section{DIAGNOSIS OF CAS IN PILOTS}

Screening for cardiac arrhythmias includes: accurate patient history and non-invasive diagnostic tests such as an ECG, 24-hour Holter monitoring and an electrocardiographic exercise test. Detection of any of these arrhythmias requires further in-depth diagnostics.

The recording of the resting (12-lead) ECG may show a number of morphological abnormalities that suggest the presence of hereditary diseases that result in ventricular arrhythmias, such as channelopathies: LQTS, SQTS, Brugada syndrome, catecholaminergic polymorphic ventricular tachycardia or cardiomyopathies: hypertrophic or arrhythmogenic right ventricular cardiomyopathy. Other electrocardiographic changes may indicate a structural heart disease, e.g. bundle branch blocks, atrioventricular blocks, ventricular hypertrophy or pathological Q-waves. Supplementing screening with 24-hour ECG monitoring increases the chances of detecting any accompanying heart rhythm disorders. In routine ECG using the Holter method in healthy subjects premature ventricular contraction is found in 40 to $80 \%$ of examinations and is correlated with age. Complex tachyarrhythmias, such as couplets or ventricular tachycardias, are no longer as common. Premature ventricular contraction (PVC) is more common in people with structural heart disease. One of the most important problems in the diagnosis of VAs is their spontaneous variability. The highest repeatability is obtained when the Holter ECG monitoring is performed for at least 48 hours, especially in the case of the number of PVCs at above 300/day [3]. Electrocardiographic examination has too little sensitivity and specificity in detecting structural heart diseases to be a sufficient stand-alone diagnostic tool for aviation medical screening. This limitation of the ECG test itself, involving the diagnosis of heart disease, was found, among others, in a Japanese study on 176 military pilots aged 4050 years. The addition of echocardiography to the standardized ECG also enabled the detection of significant left ventricular hypertrophy and left ventricular hypertrophy [26]. Echocardiographic examination is the most frequently performed imaging examination in cardiology due to its low cost and universal access. It enables detection of heart muscle diseases, acquired and congenital defects underlying or predisposing to the occurrence of arrhythmia. In order to exclude the background of ischemic arrhythmia, exercise tests are performed: electrocardiographic or imaging tests, and in many cases, coronary angiography using computed tomography. It should be noted that during the exercise test, various arrhythmias may appear, including potentially dangerous ones, such as the non-sustained ventricular tachycardia (observed in $4 \%$ of asymptomatic adults), although the mere fact of their occurrence is not associated with an increased risk of general mortality [25]. In doubtful situations, classical coronary angiography is always the decisive examination.

The legitimacy of exercise tests in pilots is reflected in the current guidelines of cardiological societies. This group has been distinguished as one of the few groups of low risk of cardiovascular diseases in which screening in the form of resting and exercise ECG is recommended [5].

Magnetic resonance imaging of the heart enables precise assessment of the size of the heart chambers, the left ventricular muscle mass and the ventricular function. It is a very good imaging method for diagnosing people with suspected cardiomyopathy. However, the best way to assess the location of the area in the heart responsible for the arrhythmia is by electrophysiological examination, which can also be used to determine the indications for ablation treatment or pacemaker implantation. In the case of ventricular arrhythmias, it is possible to document the development of ventricular tachycardia, assess the risk of its recurrence or sudden cardiac arrest, or loss of consciousness in selected patients with sus- 
Kurek M. et al. - Disorders of the electrical...

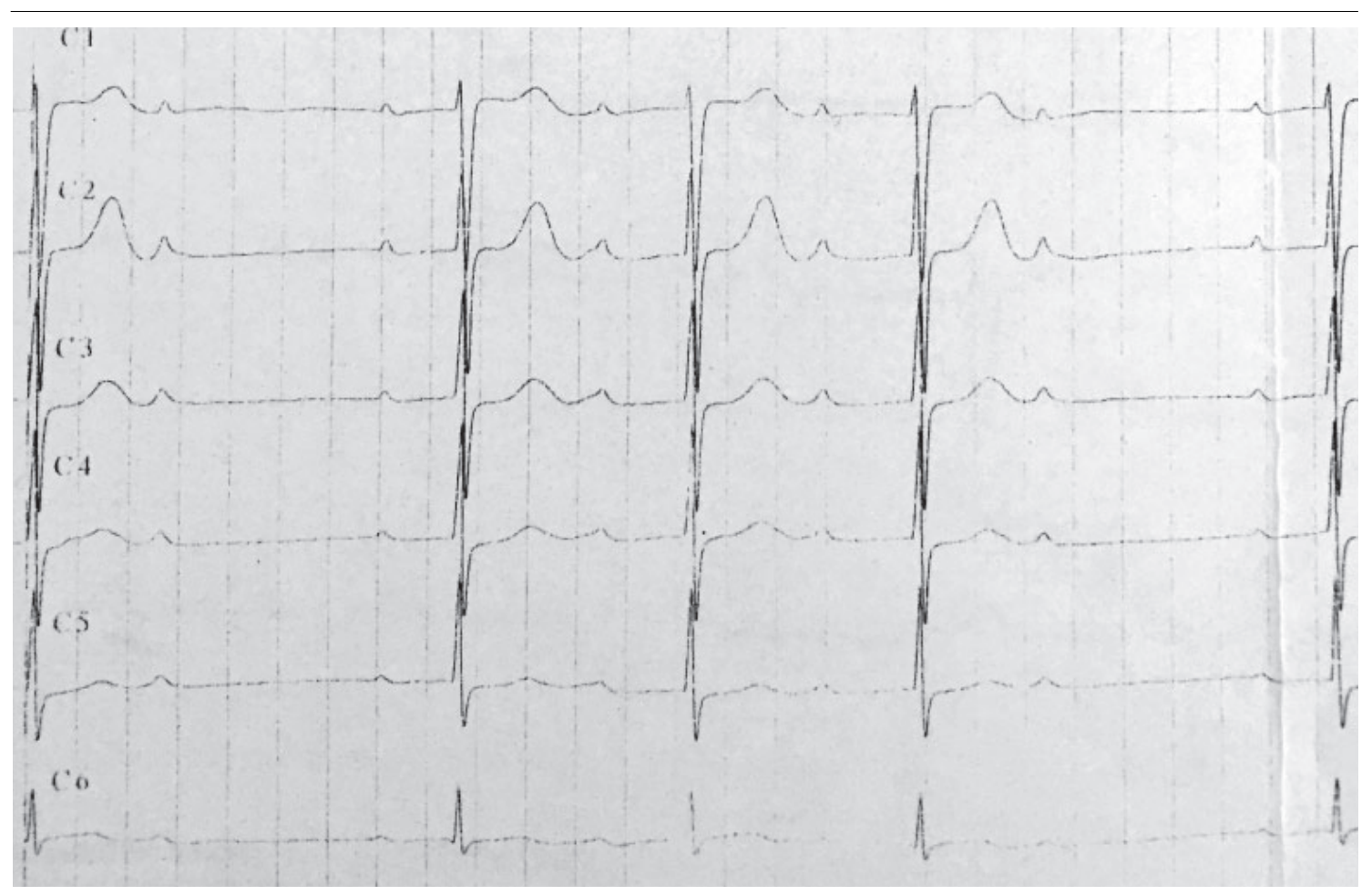

Fig. 1. Atrioventricular block of the second degree Mobitz type 1.

pected arrhythmia, and evaluate the indications for treatment with a cardioverter-defibrillator.

It should also be noted that standard diagnostic methods used to diagnose arrhythmias in pilots may not be sufficient. Pilots are subjected to high acceleration values during testing in a high-G centrifuge. During flight, accelerations in the head-leg direction - the so-called $+\mathrm{Gz}$ accelerations - are the most frequent. The influence of accelerations in the head-leg axis causes a number of hemodynamic effects as a result of displacement of a significant volume of blood circulating to the vessels of lower limbs, resulting in a decrease of venous inflow to the right half of the heart, decrease of stroke and minute volume and arterial pressure in vessels located above the heart. Increased sympathetic system tension and the release of more catecholamines change the electrophysiological parameters of the electrical conduction system and promote various cardiac arrhythmias [20]. Premature supraventricular and ventricular contractions and sinus arrythmia are the most common symptoms of $+G z$ acceleration, as well as complex arrhythmias such as paroxysmal supraventricular tachycardia, ventricular tachycardia or paroxysmal atrial fibrillation [17].

Sinus bradycardia and sinus arrythmia are often found in healthy individuals, especially those taking part in sports [10]. They remiss during the effort and are usually asymptomatic. In the case of fainting or losses of consciousness due to sinus bradycardia, sinus inhibition or sinus atrial block, further service in the air depends on the results of detailed cardiological diagnostics.

Extended PR interval, also called the atrioventricular block of the I degree, of above $200 \mathrm{~ms}$ but not exceeding $300 \mathrm{~ms}$, is a variant of the norm in the group of young, trained people [9]. If the PR interval is greater than 300 ms, an additional test such as an exercise electrocardiogram test should be performed. If the PR interval is shortened as a result of increased catecholamine release, the flight crew members are allowed to continue flight service.

In the case of atrioventricular block of the second degree Mobitz type 1 (Wenckebach Phenomenon), asymptomatic, occurring at night, no further diagnosis is necessary (Fig. 1). However, if symptoms occur and/or it takes place during the day or when they first appear after the age of 40, further cardiological diagnosis is recommended. Most people with this disorder can work in the air without restrictions.

The Mobitz type 2 atrioventricular block of the second degree and the atrioventricular block of the III degree (total) are the reason for unfitness for flying until the cause is established. They may be paroxysmal, ischemic, inflammatory, electrolytic disorder- or drug-related. In most cases, however, they are an indication for the implantation 


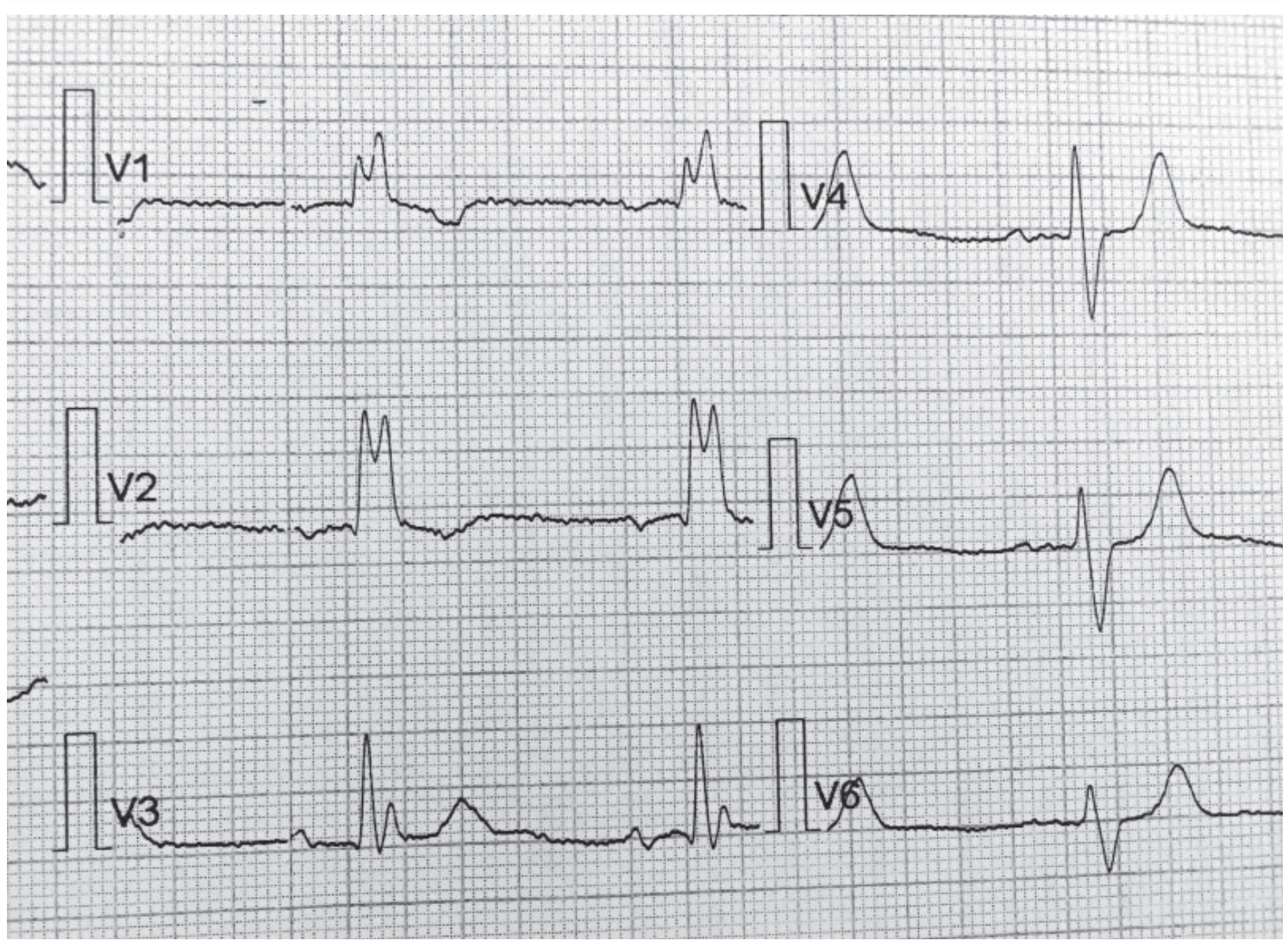

Fig. 2. Block of the right bundle branch.

of a cardiac stimulation system. Individuals with implemented pacemakers are considered unfit for flying due to the possibility of pacemaker failure and due to the influence of strong electromagnetic field present in airplanes, which may disturb the pacemaker operation [8]. In the case of persons not dependent on stimulators, there is a possibility to return to flying.

An incomplete block of the right bundle branch (Fig. 2) is a frequent change found in ECG in the general population as well as in the flying staff and does not require further diagnosis or restrictions at work [1]. The right bundle branch block requires additional tests for organic heart disease. In a 2003 study, which analyzed 2,700 military pilots for the presence of a complete block of the right bundle branch, the above disorder was detected in 36 of them. Therefore, they were subject to frequent cardiological controls with electrocardiographic exercise tests, scintigraphic exercise tests, echocardiography and in 12 cases coronary angiography [37]. In the period of observation lasting on average 11 years, no association was not found between the bundle branch block and worse prognosis. In most cases, it is not necessary to restrict the pilot license for RBBB persons.

The hemiblocks of the anterior (LAH) and posterior branch of the left bundle are most common in patients without organic heart disease [23]. Pilots with anterior block of left bundle branch have not been found to be at risk of cardiac events, sudden deaths, or progression to total bundle branch block or development of atrioventricular blocks [36]. In the case of persons of over 40 years of age, LAH may be associated with ischemic heart disease and it is therefore recommended to conduct examinations to rule it out. In the case of the posterior left bundle branch block, especially in combination with the right bundle branch block, cardiomyopathy and myocardial ischemia tests should be performed.

Left bundle branch block (LBBB) brings about the highest risk of coexistence of organic heart disease among intraventricular conduction disorders. The diagnosis of LBBB even in young patients is an indication for the performance of a broad cardiological diagnosis [21]. It may be a marker of ischemic heart disease, a result of long-lasting hypertension, aortic valve defect and cardiomyopathy [34], therefore, it is recommended to perform in this case an echo, Holter ECG, angio-CT of coronary arteries, and in some cases MRI. After the exclusion of cardiac structural disease, most of the flying staff are allowed to continue working, but more frequent cardiac checks are recommended. 
Premature supraventricular extrasystoles (PSEs) are mild arrhythmias and do not require additional diagnostics if they are rare and do not cause symptoms. With the increase in the number of PSEs, there is a tendency to an increased risk of developing atrial fibrillation, starting from a small number of beats below 100 per day, to a significant increase in the number of arrhythmias. With the number of more than 1500 beats/24 hours, no further increase in the risk of atrial fibrillation was observed [15]. Based on similar observations, more frequent aviation medical examinations with numerous premature supraventricular extrasystoles and regular Holter monitoring to detect asymptomatic atrial fibrillation are recommended.

Supraventricular tachycardia (SVT) is a rhythm disorder occurring in approximately $0.3 \%$ of adults. There are 3 forms of this arrhythmia: AVNRT atrioventricular nodal reentry tachycardia (about $60 \%$ of SVT), AVRT atrioventricular reentrant tachycardia with concomitant additional atrioventricular conduction pathway (about 30\% of SVT) and atrial tachycardia (10\% of SVT) [27]. Atrial tachycardia (Fig. 3) often occurs in people with organic heart disease, hypertension, chronic pulmonary diseases, therefore it requires first of all diagnostics in order to detect the etiology of this disorder. AVNRT and AVRT are most common in healthy individuals (without coexisting structural heart disease). Detection of this arrhythmia results in the pilot being suspend in their work until the diagnosis is completed and further action is taken. A number of external factors may influence the occurrence of a seizure of supraventricular tachycardia, such as alcohol, caffeine, supplements taken, electrolyte disturbances or hyperthyroidism. In the case of an unstable supraventricular tachycardia attack without accompanying symptoms, further flight work is allowed, although in most cases with certain limitations. In other cases, treatment is necessary. Due to the lack of sufficient effectiveness of antiarrhythmic drugs and their effect on the heart, ablation is the treatment of choice for flying staff. The efficacy of this method of treatment in the case of AVNRT and AVRT reaches 95\% [35]. Depending on the type of aircraft, most pilots can return to their previous tasks after this procedure. Limitations may appear when piloting highly maneuverable aircraft or single-seater aircraft.

In the presence of additional conduction pathways in the form of an additional muscle bundle, it is possible to stimulate the ventricle outside the physiological conduction pathways. In $98 \%$ of cases it is the bundle of Kent, while in the remaining $2 \%$ it is the Mahaim fibres. In ECG recording, the $\mathrm{PQ}$ interval is shortened below $120 \mathrm{~ms}$ and the presence of a delta wave is characteristic. If tachyarrhythmia symptoms are also present, then we are dealing with the Wolff-Parkinson-White syndrome (the WPW syndrome). In one study

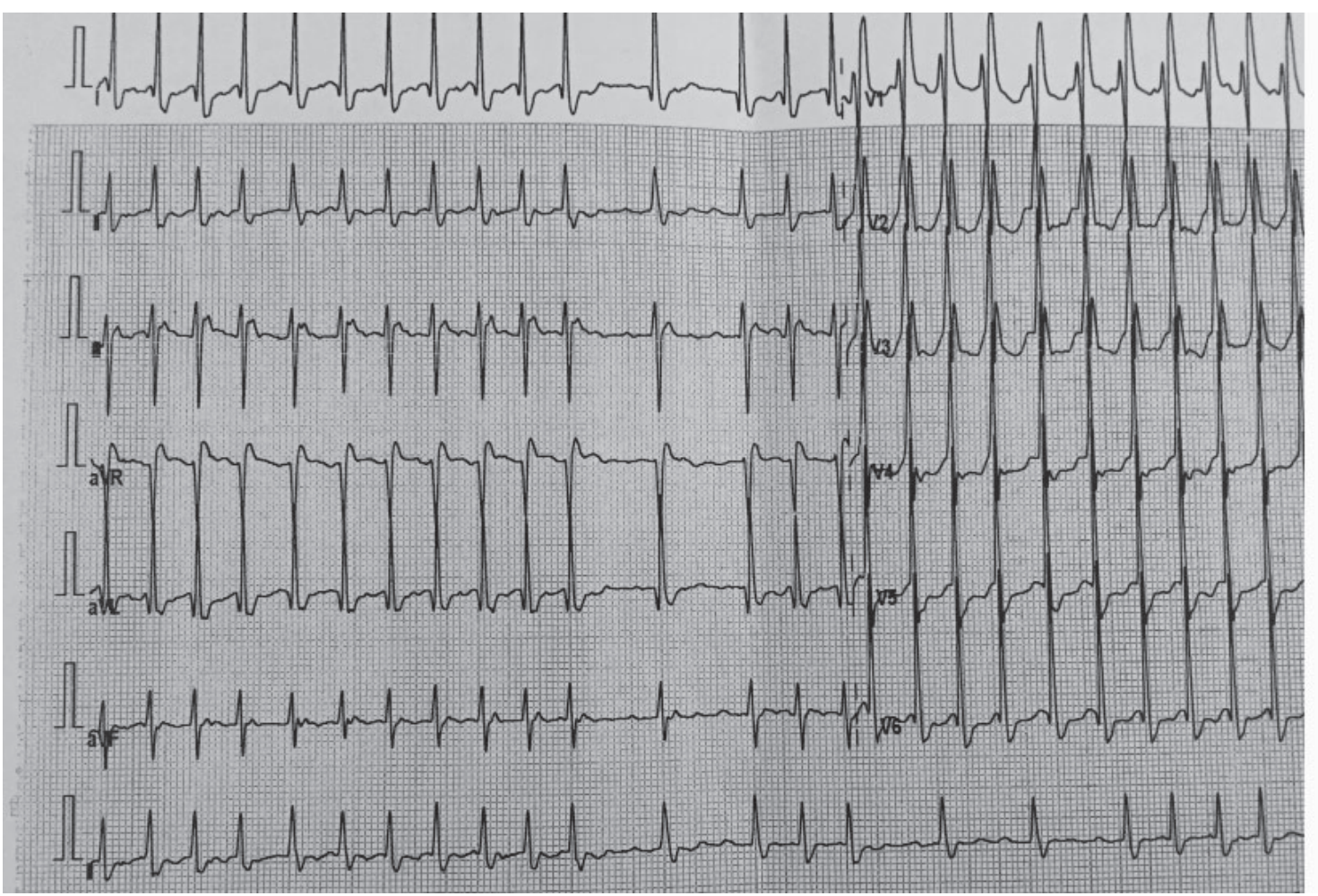

Fig. 3. Atrial tachycardia. 
in a group of 238 military pilots with WPW syndrome, the risk of sudden cardiac death of $0.02 \% /$ year was found during the observation period of 22 years. The risk of supraventricular tachycardia was estimated at 1\%/year [11]. The treatment of choice for flying staff with pre-excitation syndrome is ablation, the effectiveness of which in this disorder reaches over $98 \%$ with a very low risk of complications [4].

Atrial fibrillation (AF) is one of the most common arrhythmias found in flying staff. In a UK study published in 2012, the frequency of AF was $0.3 \%$, found in all screening ECG performed among airmen [2]. The most common form is paroxysmal atrial fibrillation without coexisting structural heart disease, the so-called spontaneous atrial fibrillation [18]. In individual cases, atrial fibrillation seizures can be linked to an obvious factor such as alcohol or medication. Since atrial fibrillation may coexist with many diseases, including: valvular heart disease, ischemic heart disease, cardiomyopathy, hypertension, hyperthyroidism or pulmonary diseases, multidirectional diagnostics is necessary in case of its occurrence [19]. The majority of antiarrhythmic drugs used in AF: flecainide, propafenone, amiodarone, dronaderone and sotalol are contraindicated in people on air duty. Only b-blockers, used mainly for rhythm frequency control, are allowed in the group of transport aircraft and helicopter pilots. Due to their chronotropic negative effect and impairment of the pressure reaction, they are prohibited for pilots of highly maneuverable aircraft. For this rea- son ablation is the preferred method of treatment for flying staff. The most frequently performed procedure is pulmonary vein isolation, the efficacy of which is about $80 \%$ [13]. After ablation, a 6-month observation period is recommended to evaluate its effectiveness. After this period, if the arrhythmia does not recur, further service in the air may be allowed, especially in the case of subsonic planes, helicopters and multi-member crews.

Atrial flutter is a disease that may accompany atrial fibrillation or occur separately. It also has similar etiology and consequences. The efficacy of pharmacological antiarrhythmic treatment in atrial flutter is even lower than in AF, therefore ablation remains the treatment of choice in flying staff. The method of treatment of atrial flutter is effective in over $90 \%$ with a relatively low risk of complications not exceeding 1\% [6].

Premature ventricular contractions (PVCs) are quite common arrhythmias (Fig. 4). It is found in about $2-7 \%$ of the population, and only in about $0.8 \%$ of pilots [39]. PVCs can occur as an isolated abnormality or as a symptom of a structural heart disease. Very numerous PVCs may lead to tachycardia-induced cardiomyopathy. The basic diagnostic examination in this arrhythmia is 24-hour Holter monitoring to assess the number of PVCs and the morphology of QRS syndromes. An exercise test is also recommended for all patients, during which the arrhythmia may be suppressed, which is considered a good prognostic symptom. In the case of frequent premature ventricular con-

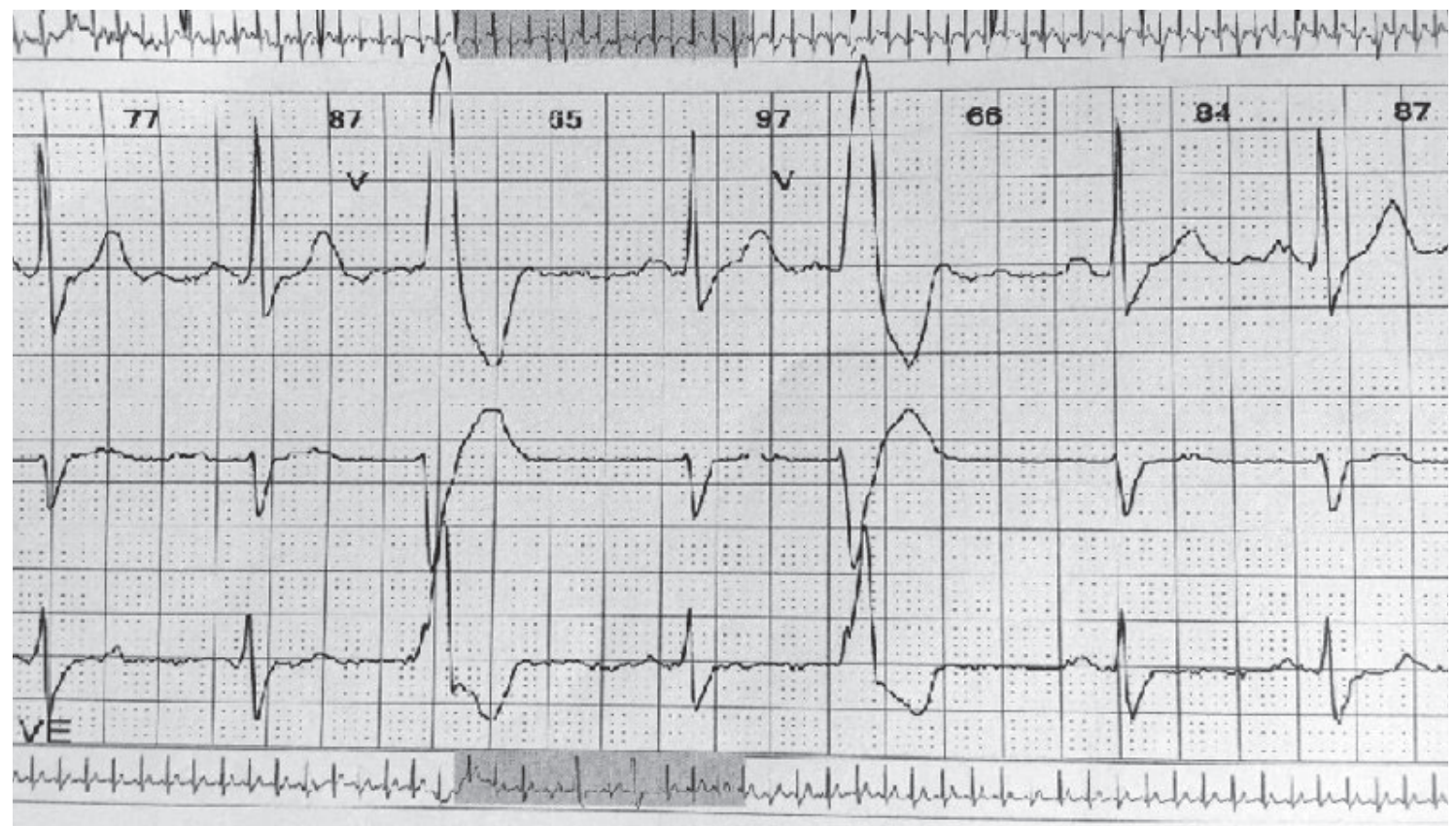

Fig. 4. Holter ECG record with 2 premature ventricular contractions. 
tractions, magnetic resonance imaging of the heart towards arrhythmogenic right ventricular cardiomyopathy is also justified [30]. It is also recommended to perform angio-CT of coronary arteries, especially in patients over 40 years of age. Not very frequent premature ventricular contractions below $2 \%$ of the total number of asymptomatic beats are usually not contraindications for airborne service. With more severe arrhythmia, especially above $7.5 \%$ of the total number of contractions, a pilot may be allowed to fly in multimember crews and on subsonic planes, transport planes and helicopters [16]. In the case of flying staff, PVC treatment is a choice between pharmacotherapy, mainly b-blockers, or ablation, which can lead to permanent remission or a significant reduction in arrhythmia. A study from 2015 showed $84 \%$ efficacy in the period immediately after ablation in individuals with numerous premature ventricular contractions (on average 20\% of all contractions). After ablation, not only did the symptoms of arrhythmia disappear, but also in patients with tachycardia-induced cardiomyopathy, the release fraction improved significantly from $38 \%$ to $50 \%$ [22].

Ventricular tachycardia (VT) is an uncommon rhythm disorder in airmen (Fig. 1). 5). During 42 years, only 193 cases of non-sustained ventricular tachycardia and no case of sustained ventricular tachycardia were recorded in the US military avia- tion [14]. During the observation, symptoms such as fainting, pre-faint condition and sudden cardiac death were observed (in these cases ischemic heart disease, mitral valve prolapse syndrome and cardiomyopathy were diagnosed as the underlying cause) in only 9 persons. Ventricular tachycardia may occur in the course of many organic heart diseases and in ion channelopathies. There is also a form of idiopathic ventricular tachycardia, which can be diagnosed after excluding other causes. Idiopathic ventricular tachycardias include VT from the right ventricular outflow pathway and idiopathic left ventricular tachycardia. Due to the limitations in the use of antiarrhythmic drugs in aviation, also in idiopathic ventricular tachycardias, the treatment of choice is ablation, the efficacy of which is $85-90 \%$ shortly after the procedure and $75-80 \%$ in the long term [38]. After a successful ablation and observation period after the surgery, there is a possibility to restore the pilot to work.

The diagnosis of any channelopathy, e.g. Long QT Syndrome (LQTS), Short QT Syndrome (SQTS), Brugada syndrome (BrS), catecholaminergic polymorphic ventricular tachycardia, is the reason for a certificate of unfitness for working in the air. This is related to the risk of sudden cardiac death in the course of ventricular tachyarrhythmia: polymorphic ventricular tachycardia and/or ventricular fibrillation. The implantation of a cardioverter-de-

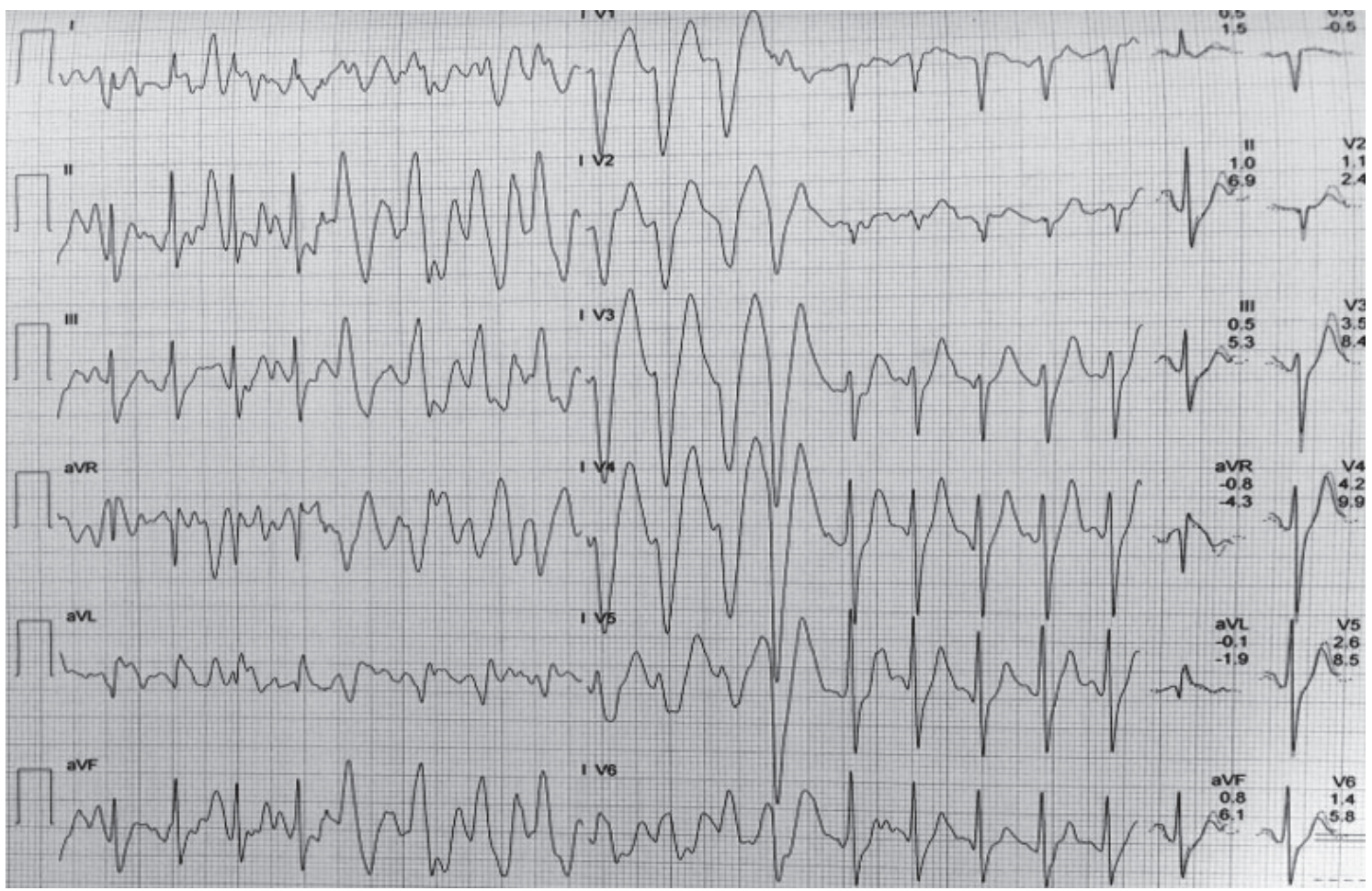

Fig. 5. ECG record of ventricular tachycardia during an exercise test. 
fibrillator is recommended for people at high risk of sudden cardiac arrest. According to current ESC guidelines, such individuals include patients with hemodynamically intolerated VT without a reversible cause, and ICD implantation should also be considered in patients with recurrent sustained VT who are undergoing optimal conservative treatment [28]. However, this does not prevent arrhythmia, and thus prevent the ICD from discharging, making it permanently inoperable.

Early ventricular repolarization syndrome is quite a problematic issue for medical certification [31]. It is also associated with an increased risk of sudden cardiac death. The higher J-point departure is quite common in persons regularly participating in sports, hence early repolarization syndrome is recommended to be diagnosed only after a documented episode of idiopathic VF or polymorphic VT in individuals with early repolarization characteristics in ECG [28].

\section{CONCLUSIONS}

The detection of mild rhythm and conduction disorders usually does not give sufficient information on further prognosis and on the ability to continue performing the tasks of a pilot. To this end, extensive research is being carried out to establish the prognostic significance of seemingly harmless arrhythmias and conduction disturbances that would not constitute any restriction on the continuation of airborne activities in the non-airborne population.

Disorders of the electrical conduction system are one of the most frequently found abnormalities during qualification and control examinations during certification. Comprehensive diagnostics of the cardiovascular system allows to distinguish abnormalities in the ECG disqualifying pilots from further flying or to qualify them as mild and not threatening further work.

\section{AUTHORS' DECLARATION:}

Study Design: Michał A. Kurek, Ewelina Zawadzka-Bartczak, Katarzyna Barwińska, Daria Owsiak; Data Collection: Michał A. Kurek, Ewelina Zawadzka-Bartczak, Katarzyna Barwińska, Daria Owsiak; Manuscript Preparation: Michał A. Kurek, Ewelina Zawadzka-Bartczak, Katarzyna Barwińska, Daria Owsiak; The Authors declare that there is no conflict of interest.

\section{REFERENCES}

1. Akparibo IY, Chumbley EM. Aerospace, Fitness for Duty, Cardiology. StatPearls [Internet]. Treasure Island (FL): StatPearls Publishing. 2018.

2. Boos $\mathrm{CJ}$, Jamil Y, Park M, et al. Electrocardiographic abnormalities in medically screened military aircrew. Aviat Space Environ Med. 2012; 83(11):1055-1059.

3. Candinas RA, Podrid PJ. Noninvasive diagnosis of ventricular arrhythmias by means of ambulatory-ECG monitoring. Herz. 1990; 15(1):1-10.

4. Chen YJ, Chen SA, Tai CT, et al. Long-term results of radiofrequency catheter ablation in patients with Wolff-Parkinson-White syndrome. Zhonghua Yi Xue Za Zhi (Taipei). 1997; 59(2):78-87.

5. Chou R, Arora B, Dana T, Fu R, Walker M, Humphrey L. Screening Asymptomatic Adults for Coronary Heart Disease With Resting or Exercise Electrocardiography: Systematic Review to Update the 2004 U.S. Preventive Services Task Force Recommendation [Internet]. Evidence Syntheses. 2011; No. 88.

6. Cosío FG. Atrial Flutter, Typical and Atypical: A Review. Arrhythm Electrophysiol Rev. 2017; 6(2):55-62

7. Dąbrowska B, Dąbrowski A. Podręcznik elektrokardiografii. Wyd. 5. PZWL. Warszawa 2005.

8. De Rotte AA, Van Der Kemp P. Electromagnetic interference in pacemakers in single-engine fixed-wing aircraft: a European perspective. Aviat Space Environ Med. 2002; 73(3):179-183.

9. Drezner JA, Ackerman M, Cannon BC, et al. Abnormal electrocardiographic findings in athletes: recognising changes suggestive of primary electrical disease. Br J Sports Med. 2013; 47(3):153-167.

10. Drezner JA, Sharma S, Baggish A, et al. International criteria for electrocardiographic interpretation in athletes: Consensus statement Br J Sports Med. 2017; 51(9):704-731. 
Kurek M. et al. - Disorders of the electrical...

11. Fitzsimmons PJ, McWhirter PD, Peterson DW, Kruyer WB. The natural history of Wolff-Parkinson-White syndrome in 228 military aviators: a long-term follow-up of 22 years. Am Heart J 2001; 142(3):530-536.

12. Fu DG. Cardiac Arrhythmias: Diagnosis, Symptoms, and Treatments. Cell Biochemistry and Biophysics. 2015; 73(2):291-296.

13. Ganesan AN, Shipp NJ, Brooks AG, et al. Long-term outcomes of catheter ablation of atrial fibrillation: a systematic review and meta-analysis. J Am Heart Assoc. 2013; 2(2):e004549.

14. Gardner RA, Kruyer WB, Pickard JS, Celio PV. Nonsustained ventricular tachycardia in 193 U.S. military aviators: Iong-term follow-up. Aviat Space Environ Med. 2000; 71(8):783-790.

15. Gladstone DJ, Dorian P, Spring M, et al. Atrial premature beats predict trial fibrillation in cryptogenic stroke: results from the EMBRACE trial. Stroke. 2015; 46(4):936-941.

16. Guettler N, Bron D, Manen O, et al. Management of cardiac conduction abnormalities and arrhythmia in aircrew. Heart. 2019; 105(Suppl 1):38-49.

17. Hanada R, Hisada T, Tsujimoto T, Ohashi K. Arrhythmias observed during high-G training: proposed training safety criterion. Aviat Space Environ Med. 2004; 75(8):688-691.

18. Hunter AH, Timperley AC, Reid AN, et al. A 5-year review of atrial fibrillation in military aircrew. Aviat Space Environ Med. 2013; 84(12):1249-1254.

19. Kirchhof P, Benussi S, Kotecha D, et al. Atrial Fibrillation 2016 (Management of) ESC Clinical Practice Guidelines. European Heart Journal. 2016; 37(38):2893-2962.

20. Kopka L. Ocena wartości metod badania układu bodźco-przewodzącego serca dla diagnostyki klinicznej i orzecznictwa lotniczo-lekarskiego. Praca habilitacyjna. WIML. Warszawa 1990.

21. Lamberti M, Ratti G, Di Miscio G, et al. Cardiovascular Risk in Young Workers with Left Bundle Branch Block. Open Journal of Preventive Medicine, 2014, 4(5):270-274.

22. Latchamsetty R, Yokokawa M, Morady F, et al. Multicenter outcomes for catheter ablation of idiopathic Tremature Ventricular Complexes. JACC Clin Electrophysiol. 2015; 1(3):116-123.

23. Maleki M, Alizadehasl A, Haghjoo M. Practical cardiology. Elsevier 2018.

24. Mantziari L, Styliadis C, Kourtidou-Papadeli C, Styliadis I. Arrhythmias, sudden cardiac death and incapacitation of pilots. Hippokratia. 2008; 12(Suppl 1):53-58.

25. Marine JE, Shetty V, Chow GV, Wright JG, Gerstenblith G, Najjar SS, Lakatta EG, Fleg JL. Prevalence and prognostic significance of exercise-induced nonsustained ventricular tachycardia in asymptomatic volunteers: BLSA (Baltimore Longitudinal Study of Aging). J Am Coll Cardiol. 2013; 62(7):595-600.

26. Ohrui N, Hisada T, Tsujimoto Y, Shinto E, Sakurai Y, Fukushima K, Miyamoto Y. Decadal electrocardiographic changes between age 40 and 50 in military pilots. Aviat Space Environ Med. 2011; 82(9):904-908.

27. Page RL, Joglar JA, Caldwell MA, et al. 2015 ACC/AHA/HRS Guideline for the Management of Adult Patients With Supraventricular Tachycardia. A Report of the American College of Cardiology/American Heart Association Task Force on Clinical Practice Guidelines and the Heart Rhythm Society. Circulation. 2016; 133(14):e506-e574.

28. Priori SG, Blomström-Lundqvist C, Mazzanti A, et al. 2015 ESC Guidelines for the management of patients with ventricular arrhythmias and the prevention of sudden cardiac death: The Task Force for the Management of Patients with Ventricular Arrhythmias and the Prevention of Sudden Cardiac Death of the European Society of Cardiology (ESC). European Heart Journal. 2015; 36(41):2793-2867.

29. Pruszczyk P, Hryniewiecki T. Wielka Interna. Kardiologia z elementami angiologii. Wyd. 2. Medical Tribune Polska. Warszawa 2018.

30. Rastegar N, Burt JR, Corona-Villalobos CP, et al. Cardiac MR findings and potential diagnostic pitfalls in patients evaluated for arrhythmogenic right ventricular cardiomyopathy. Radiographics. 2014; 34(6):1553-1570.

31. Rosso R, Kogan E, Belhassen B, et al. J-point elevation in survivors of primary ventricular fibrillation and matched control subjects: incidence and clinical significance. J Am Coll Kardiol. 2008; 52(15):1231-1238.

32. Rozporządzenie Komisji (UE) Nr 1178/2011.

33. Rozporządzenie Ministra Obrony Narodowej z dnia 24 stycznia 2018 r. w sprawie orzekania o zdolności do czynnej służby wojskowej oraz trybu postępowania wojskowych komisji lekarskich w tych sprawach (Dz.U. 2018 poz. 258).

34. Schneider JF, Thomas HE Jr, Kreger BE, McNamara PM, Kannel WB. Newly acquired left bundle-branch block: the Framingham study. Ann Intern Med. 1979; 90(3):303-310.

35. Spector P, Reynolds MR, Calkins H, et al. Meta-analysis of ablation of atrial flutter and supraventricular tachycardia. Am J Kardiol. 2009; 104(5):671-677.

36. Tamura T, Komatsu C, Asukata I, Yamamoto K, Hokari M. Time course and clinical significance of marked left axis deviation in airline pilots. Aviat Space Environ Med. 1991; 62(7):683-686. 
37. Taniguchi M, Nakano H, Kuwahara K, Masuda I, Okawa Y, Miyazaki H, Okoshi H, Kaji M, Noguchi Y, Asukata I. Prognostic and clinical significance of newly acquired complete right bundle branch block in Japan Airline pilots. Intern Med. 2003; 42(1):21-24.

38. Tondo C, Carbucicchio C, Russo AD, et al. Idiopathic Ventricular Tachycardia: Transcatheter Ablation or Antiarrhythmic Drugs? J Atr Fibrillation. 2015; 7(5):1164.

39. US Air Force. Air force waiver guide. 2017.

Cite this article as: Kurek MA, Zawadzka-Bartczak E, Barwińska K, Owsiak D. Disorders of The Electrical Conduction System of The Heart - A Significant Problem in Aviation Medicine. Pol J Aviat Med Bioeng Psychol 2018; 24(1): 21-32. DOI: 10.13174/ pjambp.06.08.2019.03 